\title{
Estimates of over-time trends in incidence and mortality of testicular cancer from 1990 to 2030
}

Qiliang Cai ${ }^{1,2 \#}$, Yegang Chen ${ }^{1 \#}$, Dingrong Zhang ${ }^{1}$, Jiancheng Pan ${ }^{1}$, Zunke Xie ${ }^{1}$, Chenjie $\mathrm{Xu}^{2}, \mathrm{Shu} \mathrm{Li}^{2}$, Xinyu Zhang ${ }^{2}$, Ying Gao ${ }^{3}$, Jie Hou ${ }^{4}$, Xuemei Guo ${ }^{5}$, Xiaodong Zhou ${ }^{1}$, Baoshuai Zhang ${ }^{6}, \mathrm{Fei} \mathrm{Ma}^{7}$, Wei Zhang ${ }^{1}$, Guiting Lin $^{8}$, Zhongcheng Xin ${ }^{1,9}$, Yuanjie Niu', Yaogang Wang ${ }^{2}$

${ }^{1}$ Department of Urology, the Second Hospital of Tianjin Medical University, Tianjin Institute of Urology, Tianjin 300211, China; ${ }^{2}$ School of Public Health, Tianjin Medical University, Tianjin 300070, China; ${ }^{3}$ Department of Health Management, Tianjin Medical University General Hospital, Tianjin 300052, China; ${ }^{4}$ School of Basic Medical Sciences, ${ }^{5}$ Library of Tianjin Medical University, Tianjin Medical University, Tianjin 300070 , China; ${ }^{6}$ Scientific Research Department, the Second Hospital of Tianjin Medical University, Tianjin 300070, China; ${ }^{7}$ Department of Epidemiology and Biostatistics, School of Public Health, Tianjin Medical University, Tianjin 300070, China; ${ }^{8}$ Knuppe Molecular Urology Laboratory, Department of Urology, School of Medicine, University of California, San Francisco, CA, USA; ${ }^{9}$ Andrology Center, Peking University First Hospital, Peking University, Beijing 100034, China

Contributions: (I) Conception and design: Q Cai, Y Chen, Z Xin, Y Niu, Y Wang; (II) Administrative support: X Zhou, B Zhang, F Ma, W Zhang, G Lin; (III) Provision of study materials or patients: Q Cai, Y Chen, J Pan, D Zhang; (IV) Collection and assembly of data: J Pan, D Zhang, Z Xie, C Xu, S Li, X Zhang, Y Gao, J Hou, X Guo; (V) Data analysis and interpretation: Q Cai, Y Chen, J Pan, D Zhang; (VI) Manuscript writing: All authors; (VII) Final approval of manuscript: All authors.

\#These authors contributed equally to this work.

Correspondence to: Prof. Yuanjie Niu. Department of Urology, the Second Hospital of Tianjin Medical University, Tianjin Institute of Urology, Tianjin 300211, China. Email: qlcwwtg@gmail.com; Prof. Yaogang Wang. School of Public Health, Tianjin Medical University, Tianjin 300070, China. Email: wyg@tmu.edu.cn.

Background: This study aims to explore and project the temporal trends in incidence and mortality of testicular cancer. Moreover, it can provide theoretical guidance for the rational allocation of health resources. Methods: This study analyzed existing data on testicular cancer morbidity and mortality from 1990 to 2016 and predicted time-varying trends of age-standardized incidence rate (ASIR) and age-standardized death rate (ASDR) from 2017 to 2030 in different ages, regions and sociodemographic index (SDI) quintile sub-groups. Result: Globally, numbers of testicular cancer cases in 2016 [66,833; 95\% uncertainty interval (UI), 64,48769,736] are 1.8 times larger than in $1990(37,231 ; 95 \%$ UI, 36,116-38,515). The testicular cancer-related death cases increased slightly from 8,394 (95\% UI, 7,980-8,904) in 1990 to 8,651 (95\% UI, 8,292-9,027) in 2016. In aspect of ASIR, the data showed an up-trend from 0.74 (95\% UI, 0.72-0.77) in 1990 to 0.88 (95\% UI, 0.85-0.92) in 2016. The ASDR of testicular cancer declined from 0.18 (95\% UI, 0.17-0.19) in 1990 to 0.12 (95\% UI, 0.11-0.12) in 2016. From 2017 to 2030, predictions of trends in testicular cancer indicate that the ASIRs of most SDI countries are rising, but the ASDRs trends in testicular cancer will decrease.

Conclusions: By analyzing the available and reliable data in different ages, regions and SDI, this study shows a significant upward trend in incidence and a slow upward trend in mortality of testicular cancer from 1990 to 2016, and simultaneously, predicts the increase of ASIR and the downward trend of ASDR in 20172030.

Keywords: Testicular cancer; incidence; mortality; trend; projection

Submitted Jan 29, 2020. Accepted for publication Feb 14, 2020.

doi: $10.21037 /$ tau.2020.02.22

View this article at: http://dx.doi.org/10.21037/tau.2020.02.22 


\section{Introduction}

Testicular cancer, especially testicular germ cell tumor (TGCT), often happens in young and middle-aged men, and has a higher treatable rate than other cancer (1). The high survival rates contribute to the long-term burden of this cancer: patients often suffer from infertility, sexual dysfunction, and many other unknown treatment complications (2-4). In 2019, according to the latest data from 2002 to 2016, it is estimated that there will be 9,560 new cases of testicular cancer worldwide, of which 410 may be killed (5). In general, the incidence rates of testicular cancer appear to increase over time: for example, the incidence in the United States had increased steadily for about 10 years, and this growth trend will continue in the next 10 years (6).

Some studies researched this disease by analyzing the burden of testicular cancer in which is primarily confined to a country or a certain region $(7,8)$. We collected data from the Global Burden of Disease data base (GBD), analyzed the temporal trends and simultaneously, estimated the incidence and death rates of testicular cancer in the next few years by 2030. Moreover, this study analyzed the temporal trends in several subgroups, including age, region, and sociodemographic index (SDI: a summary indicator of income per capita, educational attainment, and fertility). Understanding these factors is essential to provide the information about testicular cancer etiologies and the different changes in different subgroups.

Due to enormous cancer-relate economic burden, appropriate policies need to be developed to address this health issue so that health resource can be reasonably allocated. For this reason, the results of this study are sufficient to guide healthcare decisions and adjust implement plans.

\section{Methods}

Our research team collected the reliable data on testicular cancer in GBD. Many methods of analysis and estimation of existing data have been previously reported (9-14). The current study complies with the Guidelines for Accurate and Transparent Health Estimates Reporting (GATHER) (15). This time series is re-estimated overall compared to the published studies $(16,17)$, and the results revealed by this study may replace previous studies. Testicular cancer is divided into 4 groups in incidence including C62-C62.92, Z80.43, Z85.47-Z85.48 in ICD-10 by International
Classification of Diseases (ICD), and 4 cancer groups in mortality including C61-C61.9, D07.5, D29.1, D40.0 in ICD-10. Based on the collected data, we predict the disease burden of testicular cancer in different SDI countries and regions. The rates are calculated per 100,000 person-years. Age-standardized rates are calculated according to the GBD world population standard (18). Uncertainty intervals (UIs) are also reported.

Estimation process reported by this study begins with cancer mortality. Data sources of cancer mortality include vital registration systems ( $84 \%$ of data in 2016), cancer registries (16\% of data in 2016), and verbal autopsy data $(0.7 \%$ of data in 2016). Cancer incidence data are used to estimate mortality in some places where do not contain cancer death data by multiplying incidence by mortality-to incidence ratio. Cause of death ensemble model (CODEm) also can be appropriate for the death estimated data $(11,19)$. Using the mortality-incidence rate (MIR) divides final cancer-specific mortality estimates to estimate cancer incidence. Statistical programming was done using the $\mathrm{R}$ statistical program version 3.4 and SAS version 9.3. Related methodological details can be found in Supplementary materials.

\section{Results}

\section{Over-time trends in incidence cases of testicular cancer from 1990 to 2016}

Globally, there were 66,833 (95\% UI, 64,486-69,736) incident cases of testicular cancer in 2016, 1.8 times the numbers of new cases in 1990 (66,833; 95\% UI, 64,487$69,736)$. Overall, $2.3 \%$ of this increase was due to changes in the population age structure, $12.4 \%$ was due to changes in the population size, and $15.8 \%$ was due to changes in the incidence rates (Tables $S 1-S 9$ in Supplementary materials and table online: http://fp.amegroups.cn/cms/236a29d20a 4eb14f040340fbf5255b3b/tau.2020.02.22-1.docx). Among regions, the largest increase in incident cases from 1990 to 2016 occurred in Central Latin America, increased by $576 \%$ from 718 (95\% UI, 682-7,598) in 1990 to 4,856 (95\% UI, 4,571-5,151) in 2016. In terms of absolute numbers, high-income North America had the most cases of testicular cancer for males in 2016 (14,680; 95\% UI, 13,694-15,690), followed by Western Europe (14,417; 95\% UI, 13,25116,174) and East Asia (5,381; 95\% UI, 4,977-5,782). In Oceania, the number was only 48 (95\% UI, 41-54). Among SDI countries, the largest increase in incident cases $(224 \%)$ 
happened in middle SDI countries [from 3,629 (95\% UI, $3,423-4,031)$ in 1990 to 11,740 (95\% UI, $11,334-12,177)$ in 2016], followed by high-middle SDI, middle SDI, lowmiddle SDI and low SDI (Table 1).

\section{Over-time trends in mortality cases of testicular cancer from 1990 to 2016}

Globally, testicular cancer caused 8,651 deaths (95\% UI, $8,292-9,027)$ in 2016 , but in 1990 , that number was 8,394 (95\% UI, 7,980-8,904). In terms of regions, regions with the highest number of deaths are South Asia $(2,064 ; 95 \%$ UI, 1,878-2,285), Central Latin America (749; 95\% UI, 679-848), and South Asia (683; 95\% UI, 640-727). The mortality rates of low SDI, low-middle SDI and middle SDI increased slightly, but the mortality rates of high SDI and high-middle SDI decreased from 1990 to 2016. The Middle SDI countries had the greatest number of death cases followed by low-middle SDI, high-middle SDI, high SDI and low SDI countries. Deaths from high and high-middle SDI countries were declined by 333 and 193, respectively (Table 1).

\section{Over-time trends in age-standardized incidence (ASIR) of testicular cancer from 1990 to 2016}

The ASIR increased by $18.92 \%$ from 0.74 (95\% UI, $0.72-$ 0.77 ) in 1990 to 0.88 (95\% UI, 0.85-0.92) in 2016 all over the world (Table 2). Among regions, the 3 highest ASIR of testicular cancer were Southern Latin America (9.11; 95\% UI, 8.04-10.24), high-income North America (8.26; 95\% UI, 7.70-8.84), and Central Europe (7.05; 95\% UI, 6.43-7.77). Between 1990 and 2016, the highest changes in ASIR occurred in middle SDI countries and Central Latin America. For SDI countries, the rapid change is in Middle SDI countries, reaching $113 \%$, and the growth in other SDI countries also appeared obviously (Figures 1,2 and Table 2).

\section{Over-time trends in age-standardized death rate (ASDR) of testicular cancer from 1990 to 2016}

Globally, the change in ASDR decreased by $57.14 \%$ from 0.18 (95\% UI, 0.17-0.19) in 1990 to 0.12 (95\% UI, $0.11-0.12$ ) in 2016 (Table 2). Among regions, the 3 highest ASDR happened in Southern Latin America (0.97; 95\% UI, 0.82-1.16), Central Latin America (0.62; $95 \%$ UI, 0.57-0.69), and Central Europe (0.60; 95\% UI, 0.55-0.65). However, ASDR has decreased steeply in most regions, and most of this change in East Asia is about $66.67 \%$. The highest increasing changes of ASDR occurred in Central Latin America. In addition, the average annual percentage change in ASDR of testicular cancer by geography and gender displayed a significant increase in North America, South America and Central Africa. Compared with China, the rise of ASDR in America was higher than in China in both sexes and only males. In SDI countries, High-middle SDI showed the largest reduction in ASDR, about 43.48\%, and other SDI countries have changed by about $30 \%$ from 1990 to 2016 (Figures 2,3 and Table 2).

\section{Over-time trends in projection of testicular cancer from 2017 to 2030}

This study also forecasts the trends in the ASIR and ASDR of testicular cancer from 2017 to 2030. At the global level, ASIR will maintain steady growth, while ASDR will fall more sharply. Testicular cancer will most often occur in developed countries by 2030, and at the same time, the incidence will continue to increase in male. From 2017 to 2030, ASIR will rise in most of SDI countries while the low SDI and low-middle SDI countries will be different, where they will remain stable. However, the largest ASDR decrease will occur in high-middle SDI, followed by low SDI, low-middle SDI, and the high SDI, high-middle SDI future trend also remain stable. It should be noted that the changing trend within $95 \%$ UI can't be ignored. Actual changes are likely to fluctuate within this range and may differ from the trends predicted above (Figure 4).

\section{Discussion}

Testicular cancer is the most common cancer in young and middle-aged men. Although curable, illness or treatment or both can impose huge physical, psychological and financial burdens on patients, especially young people. Although the incidence of testicular cancer accounts for only $1 \%$ of all cancers, it has received increasing attention due to its severe consequences. However, many prior researches lacked attention to trends in the incidence and mortality rates of testicular. According to literature, this is the first study to systematically analyze the incidence and death rates between 1990 and 2016 by ages, SDI countries, and regions. The testicular cancer incidence trend indicates that from 1990 through 2016, especially in adolescence and young people ( $<49$ years old), the incidence increased significantly. The key reason for the increase in incident cases is the 


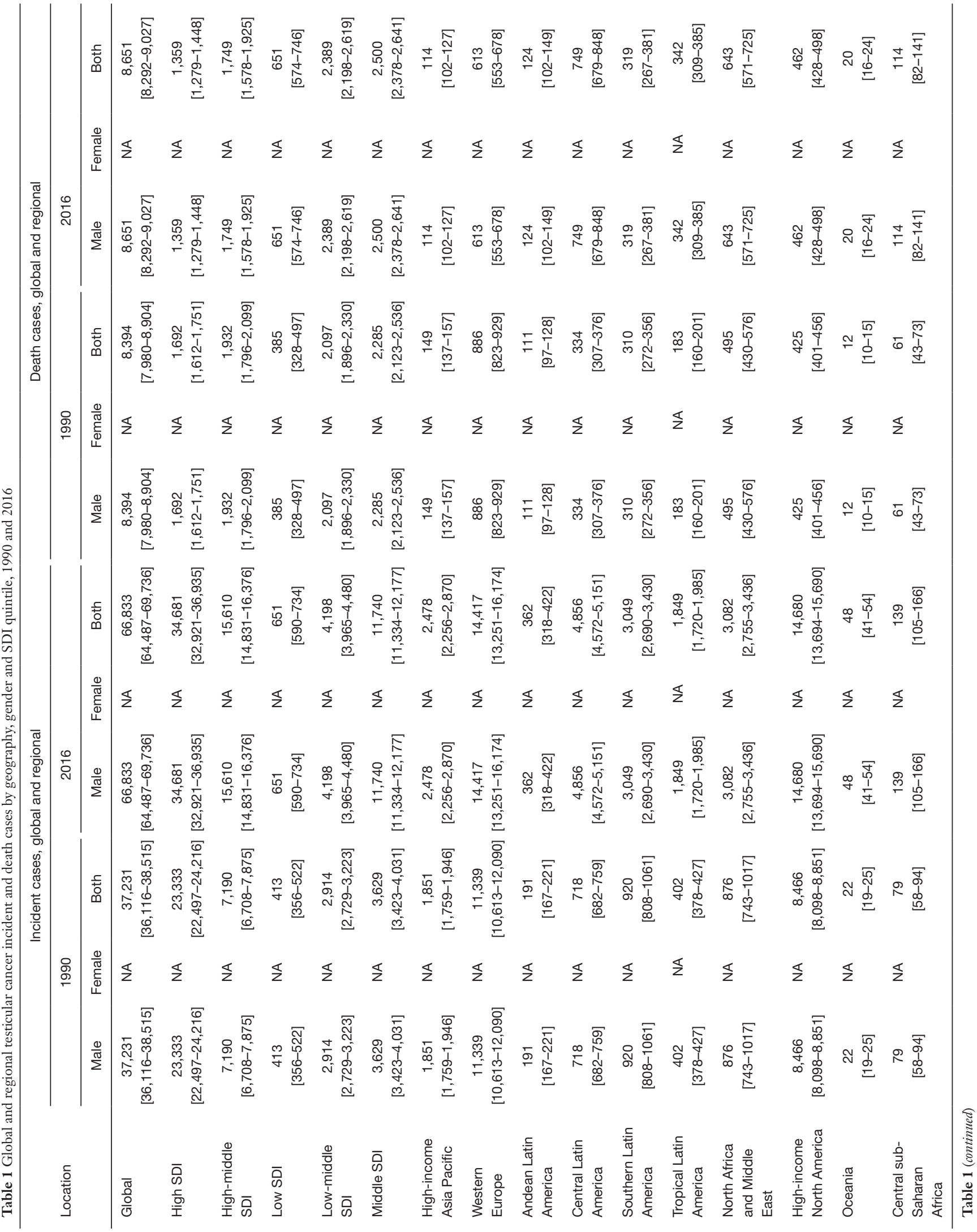




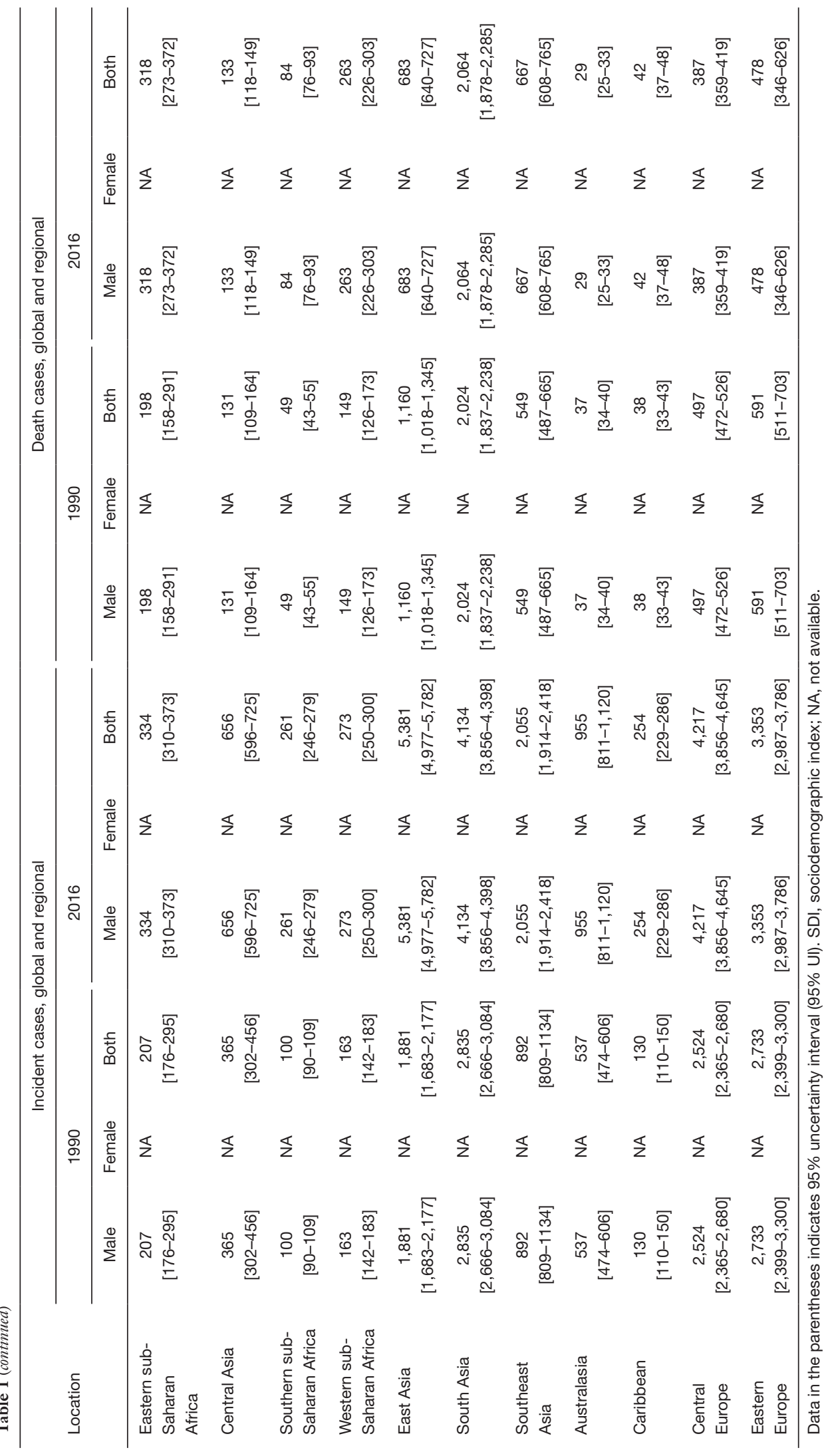


Table 2 Global and regional age-standardized testicular cancer incidence and death rates with $95 \%$ uncertainty interval and percent change by SDI and sex between 1990 and 2016

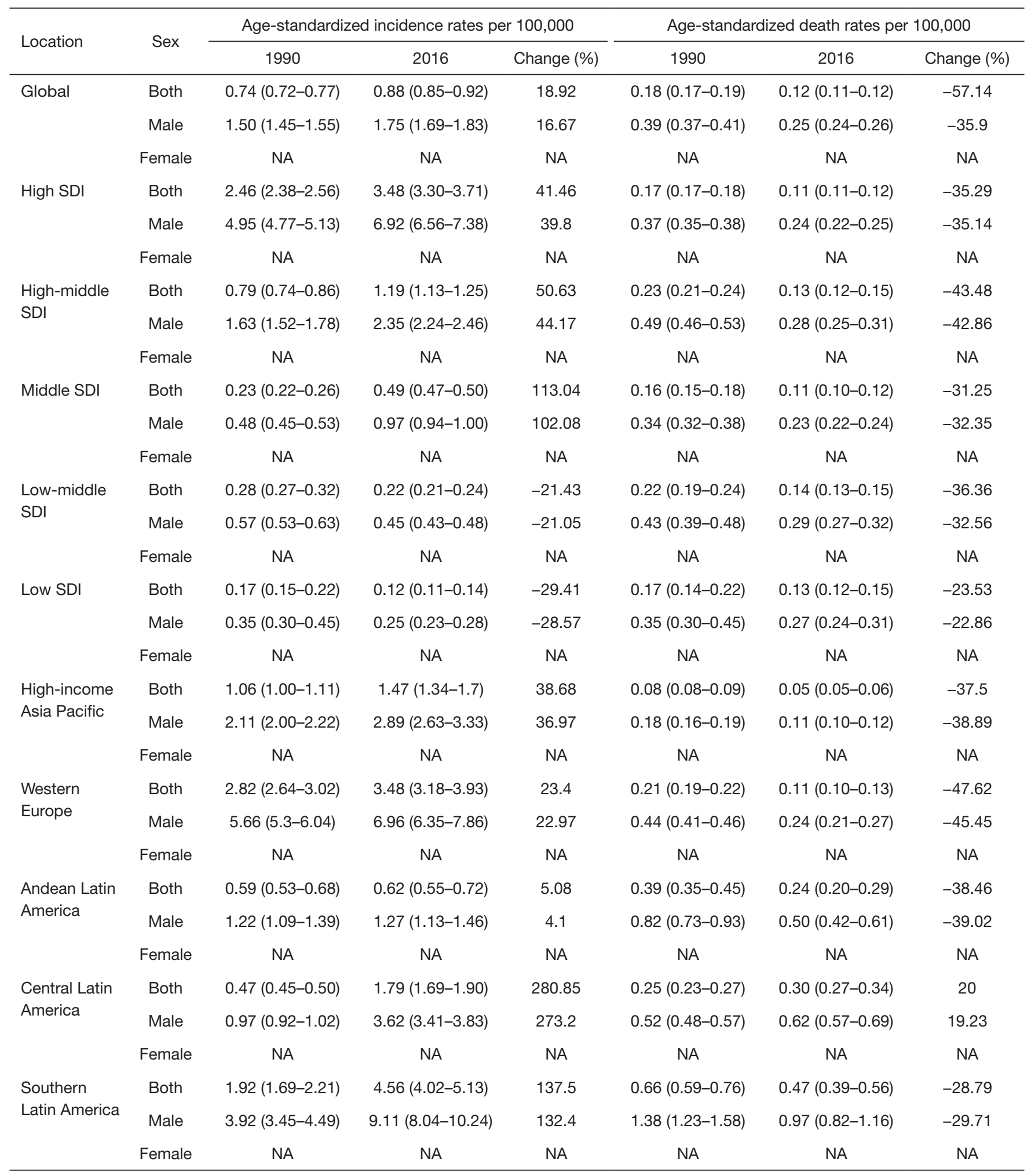

Table 2 (continued) 
Table 2 (continued)

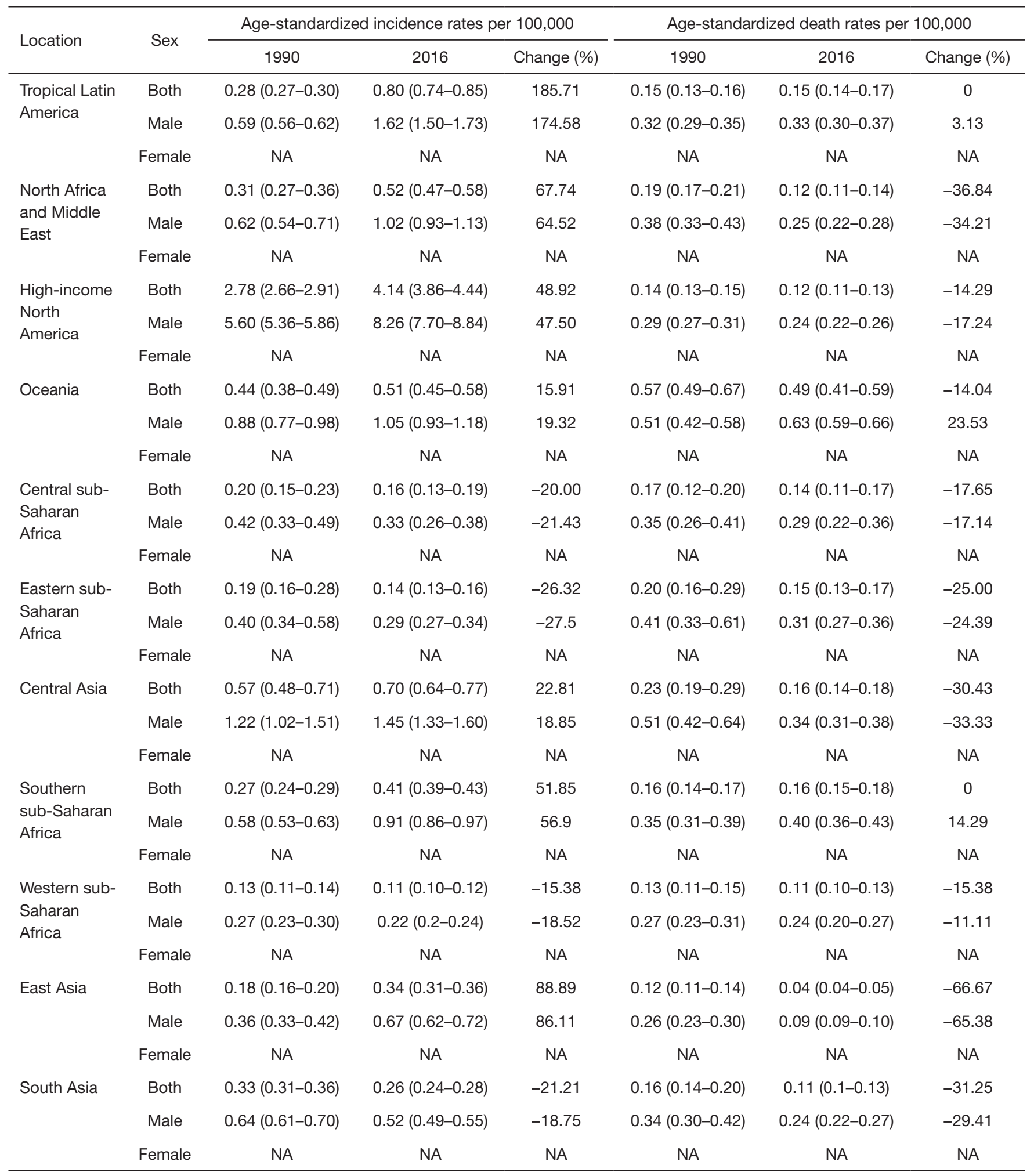

Table 2 (continued) 
Table 2 (continued)

\begin{tabular}{|c|c|c|c|c|c|c|c|}
\hline Location & Sex & \multicolumn{3}{|c|}{ Age-standardized incidence rates per 100,000} & \multicolumn{3}{|c|}{ Age-standardized death rates per 100,000} \\
\hline \multirow{3}{*}{$\begin{array}{l}\text { Southeast } \\
\text { Asia }\end{array}$} & Both & $0.24(0.22-0.30)$ & $0.31(0.29-0.37)$ & 29.17 & $0.16(0.14-0.20)$ & $0.11(0.10-0.13)$ & -31.25 \\
\hline & Male & $0.50(0.45-0.63)$ & $0.65(0.61-0.76)$ & 30.00 & $0.34(0.30-0.42)$ & $0.24(0.22-0.27)$ & -29.41 \\
\hline & Female & NA & NA & NA & NA & NA & NA \\
\hline \multirow{2}{*}{ Australasia } & Male & $4.88(4.33-5.51)$ & $6.57(5.52-7.72)$ & 34.63 & $0.35(0.32-0.38)$ & $0.18(0.16-0.21)$ & -48.57 \\
\hline & Female & NA & NA & NA & NA & NA & NA \\
\hline \multirow[t]{2}{*}{ Caribbean } & Both & $0.37(0.32-0.42)$ & $0.55(0.5-0.62)$ & 48.65 & $0.12(0.11-0.14)$ & $0.09(0.08-0.11)$ & -25.00 \\
\hline & Male & $0.76(0.65-0.87)$ & $1.12(1.01-1.25)$ & 47.37 & $0.25(0.22-0.28)$ & $0.19(0.17-0.22)$ & -24.00 \\
\hline \multirow{2}{*}{$\begin{array}{l}\text { Central } \\
\text { Europe }\end{array}$} & Male & $4.07(3.82-4.32)$ & $7.05(6.43-7.77)$ & 73.22 & $0.83(0.79-0.87)$ & $0.60(0.55-0.65)$ & -25.29 \\
\hline & Female & NA & NA & NA & NA & NA & NA \\
\hline \multirow{3}{*}{$\begin{array}{l}\text { Eastern } \\
\text { Europe }\end{array}$} & Both & $1.18(1.03-1.42)$ & $1.43(1.27-1.60)$ & 21.19 & $0.25(0.22-0.30)$ & $0.19(0.14-0.25)$ & -24 \\
\hline & Male & $2.54(2.24-3.03)$ & $2.97(2.64-3.32)$ & 16.93 & $0.60(0.52-0.71)$ & $0.43(0.31-0.56)$ & -28.33 \\
\hline & Female & NA & NA & NA & NA & NA & NA \\
\hline
\end{tabular}

Data in the parentheses indicates $95 \%$ uncertainty interval (95\% UI). SDI, sociodemographic index; NA, not available.

change in incidence rate, followed by population growth and change in age structure. However, with the growth of the economy and the advancement of medical technology, the trend of death worldwide is falling sharply. In this study, Among SDI countries, the largest increase in incident cases was in middle SDI and high SDI countries. Among the regions, incident cases in America and many Europe countries increased commonly from 1990 to 2016. In 2016, there were 66,833 testicular cancer events worldwide. Its incidence may not be enough to cause more concern than other common cancers, but TGCT is the most common solid tumor in men between the ages of 20 and 34 . Overall, research related to testicular cancer is insufficient.

It has been reported in previous study that the cancer outcomes are strongly correlated with the health care expenditures, adequate diagnosis and treatment services (20). Generally, developed countries invest more in health and also have more advanced treatment and diagnostic methods. Moreover, with increasing investment in health and advances in medical technology in developing countries, the future trend of ASDR worldwide and in each country is declining. These conjectures explain the above situation well, while it is not easy to explain it perfectly.

The two most influential factors are population growth and changes in age structure during the development of testicular cancer incidence. But, these two reasons contribute differently at different ages, regions and SDI countries. There are many other risk factors for the occurrence of seminoma or nonseminoma in germ cell tumors (GCTs). For example, several environmental risk factors are independently associated with testicular cancer. The most common include cryptorchidism, low birth weight and short gestational age (21). Cryptorchidism can induce ipsilateral and contralateral testicular cancer (22), and Testicular microlithiasis may often coexists with this disease (23). The genetic factors also play a role in testicular cancer, while only $5 \%$ of patients diagnosed with this disease are considered to have inherent relation. People whose father has testicular cancer are 4 to 6 times more likely to develop the disease than normal people, and if a brother has this cancer, the risk would become 8 to 10 times (24). Furthermore, Down syndrome, Klinefelter's syndrome and testicular dysgenesis syndrome are also associated with 
Total

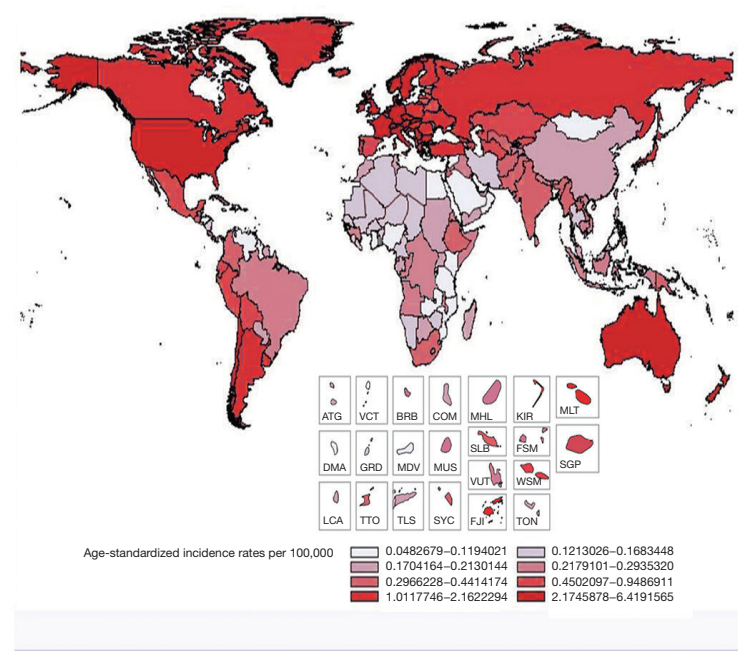

2016

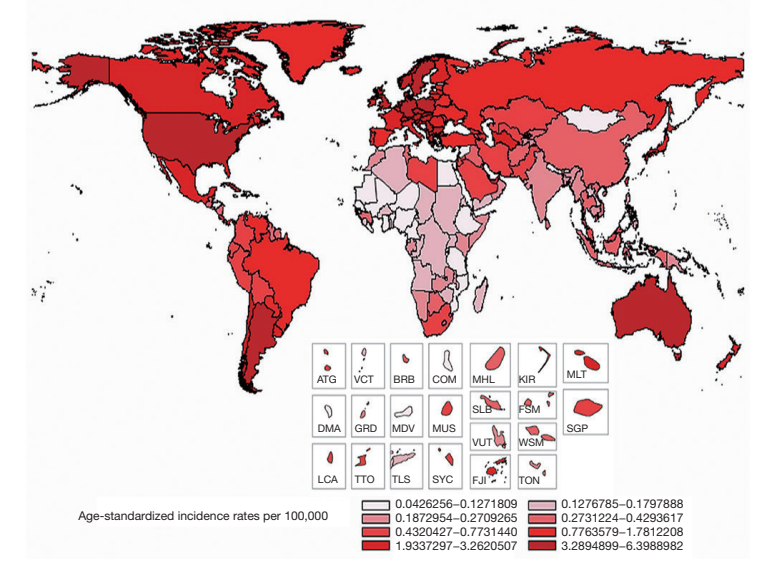

Male
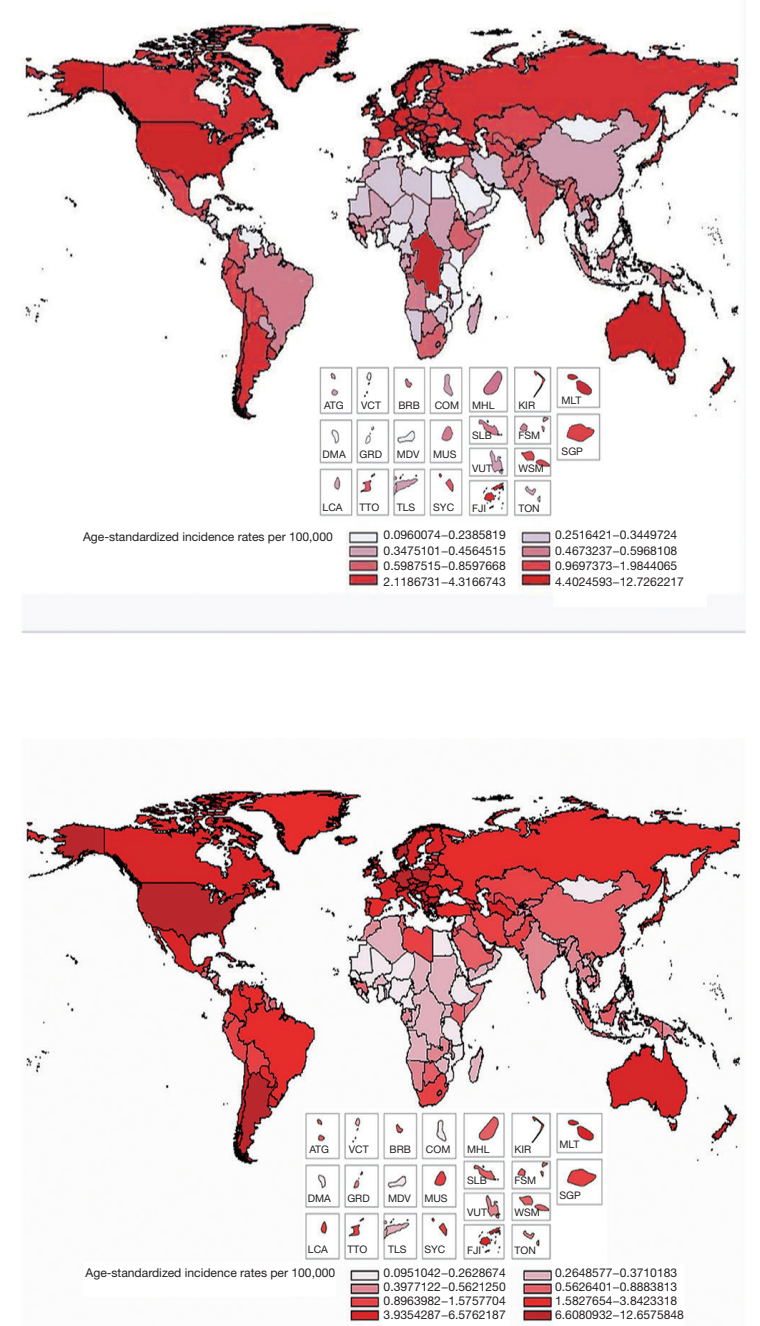

Figure 1 Global and regional testicular cancer ASIR by geography and gender, 1990 and 2016. ASIR, age-standardized incidence rate; ATG, Antigua and Barbuda; VCT, Saint Vincent and the Grenadines; BRB, Barbados; COM, Comoros; MHL, Marshall Islands; KIR, Kiribati; MLT, Malta; DMA, Dominica; GRD, Grenada; MDV, Maldives; MUS, Mauritius; SLB, Solomon Islands; FSM, Federated States of Micronesia; VUT, Vanuatu; WSM, Samoa. SGP, Singapore; LCA, Saint Lucia; TTO, Trinidad and Tobago; TLS, Timor-Leste; SYC, Seychelles; FJI, Fiji; TON, Tonga.

increased risks of testicular cancer (25-27). In addition, mother's weight gain during pregnancy, estrogen level, race, birth weight, social life status, education levels, serum cholesterol level and lifestyle are all associated with testicular neoplasms (28-34). Screening has not yet taken place globally, and prevention recommendations are also not enough in all regions.

Testicular cancer mortality may be impacted by multiple factors. For example, the living environment change is an important influencing factor. But the harmful factors are still existence in lifestyles such as tobacco smoking, obesity, hypertension and high fat diet (35). Furthermore, the high body mass index (BMI), sport absence and sedentariness were also considered to increase the mortality in this cancer, while the evidences were insufficient compared to other urologic cancers. However, the most established risk factor remains cryptorchidism. The favorable trends in mortality are largely due to the introduction (since the 
A

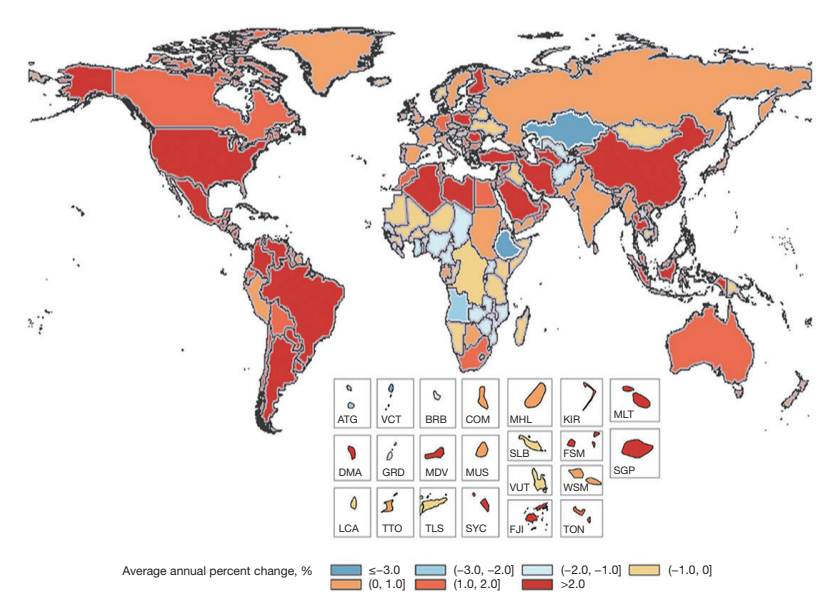

B

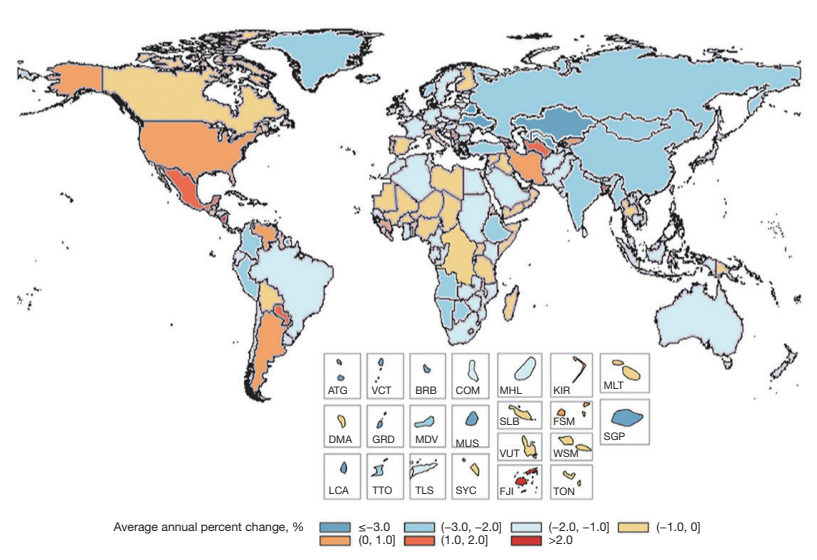

Male

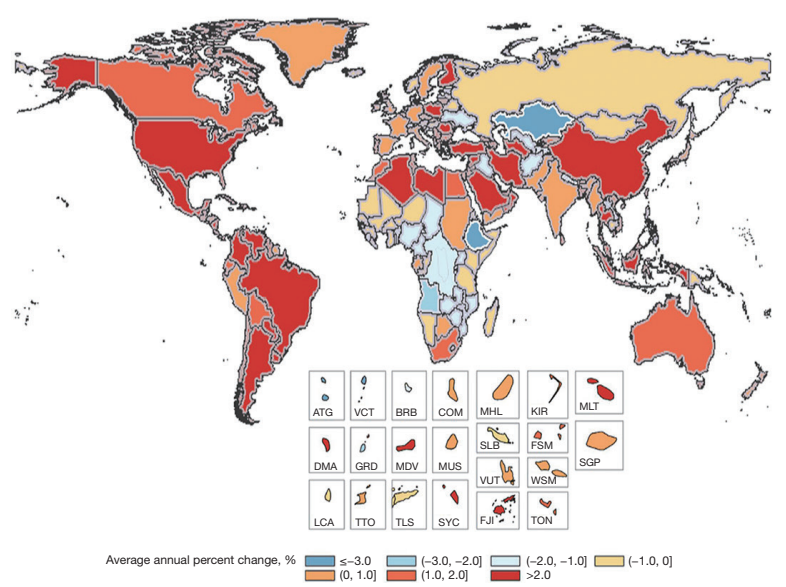

Male

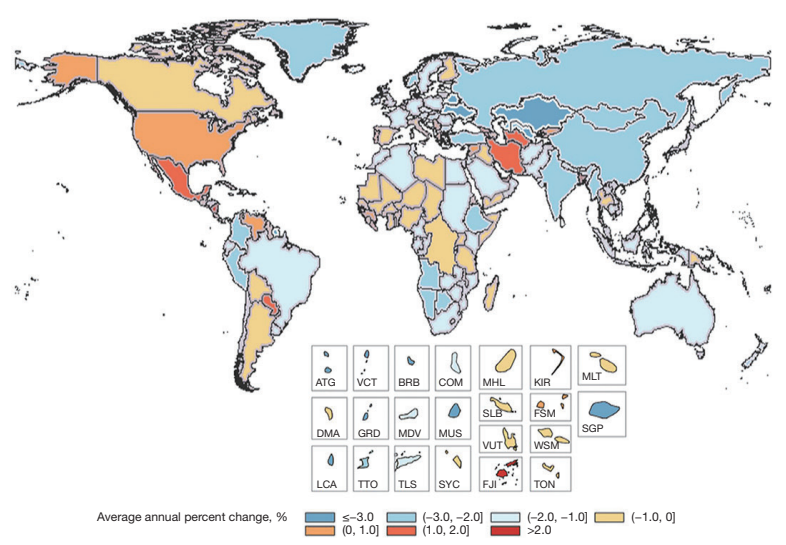

Figure 2 Global and regional average annual percent change in age-standardized incidence and death rates for testicular cancer by geography and gender, 1990-2016. (A) Average annual percent change in age-standardized incidence rates for testicular cancer by geography and gender, 1990-2016; (B) average annual percent change in age-standardized death rates for testicular cancer by geography and gender, 1990-2016. ATG indicates Antigua and Barbuda; VCT, Saint Vincent and the Grenadines; BRB, Barbados; COM, Comoros; MHL, Marshall Islands; KIR, Kiribati; MLT, Malta; DMA, Dominica; GRD, Grenada; MDV, Maldives; MUS, Mauritius; SLB, Solomon Islands; FSM, Federated States of Micronesia; VUT, Vanuatu; WSM, Samoa. SGP, Singapore; LCA, Saint Lucia; TTO, Trinidad and Tobago; TLS, Timor-Leste; SYC, Seychelles; FJI, Fiji; TON, Tonga.

1970s) of effective treatments, mainly platinum-derived chemotherapy.

This study shows future trends in testicular cancer. Trends are predicted by statistical methods and professional tools, and the feasibility ensured by analyzing. As mentioned above, the reason for the increasing incidence is likely to be related to the risk factors brought about by social development. However, the reason for the declining mortality rate can still be explained by development of economic and medical technological, but the specific reasons for the small change in the incidence of low SDI and low middle-SDI countries may be related to population size and local customs. To the best of my knowledge, this research is the first to analyze the temporal trends of 

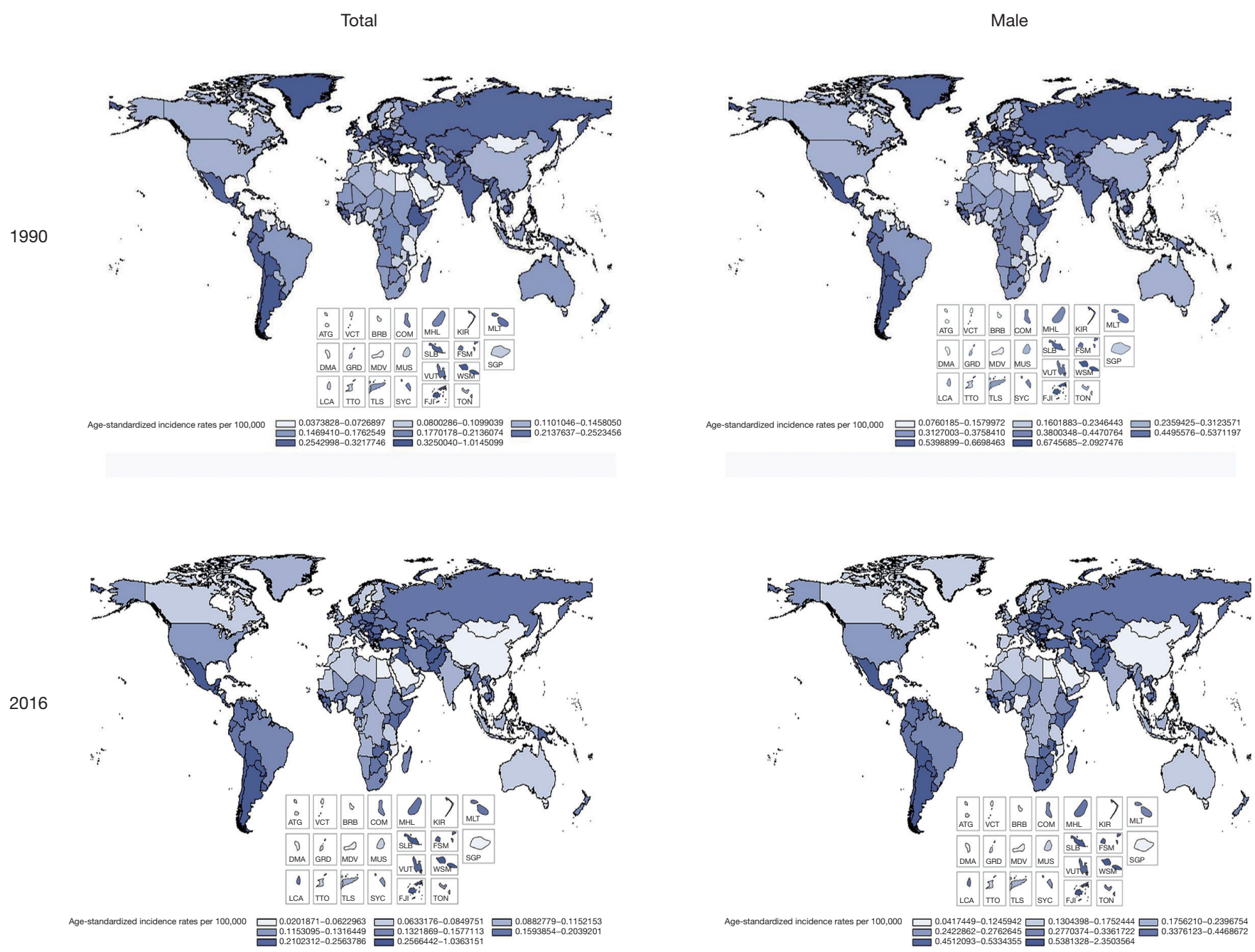

Figure 3 Global and regional testicular cancer ASDR by geography and gender, 1990 and 2016. ASDR, age-standardized death rate; ATG, Antigua and Barbuda; VCT, Saint Vincent and the Grenadines; BRB, Barbados; COM, Comoros; MHL, Marshall Islands; KIR, Kiribati; MLT, Malta; DMA, Dominica; GRD, Grenada; MDV, Maldives; MUS, Mauritius; SLB, Solomon Islands; FSM, Federated States of Micronesia; VUT, Vanuatu; WSM, Samoa. SGP, Singapore; LCA, Saint Lucia; TTO, Trinidad and Tobago; TLS, Timor-Leste; SYC, Seychelles; FJI, Fiji; TON, Tonga.

testicular cancer incidence and mortality from 1990 to 2030. This article analyzes the trends of different subgroups including ages, regions and SDI from 1990 to 2030 by combining existing data and estimated data. The time trends presented the testicular cancer epidemiology and can guide intervention programs and instruct cancer determinants and outcomes research. Trends in cancer incidence will assist with resource allocation as a window into the future, which is essential for health policy, screening guidelines, and resource allocation decisions.

\section{Conclusions}

After detailed analysis of temporal trends in collecting and predicting data on future testicular cancer incidence and death rate in 2030, the outcomes show that the global incidence increased significantly in terms of population expansion and age structure changes, but not for multifactor mortality. This has led to serious economic problems in treatment and supportive therapies, and challenges to all segments of society. As the first systematic summary of 
A
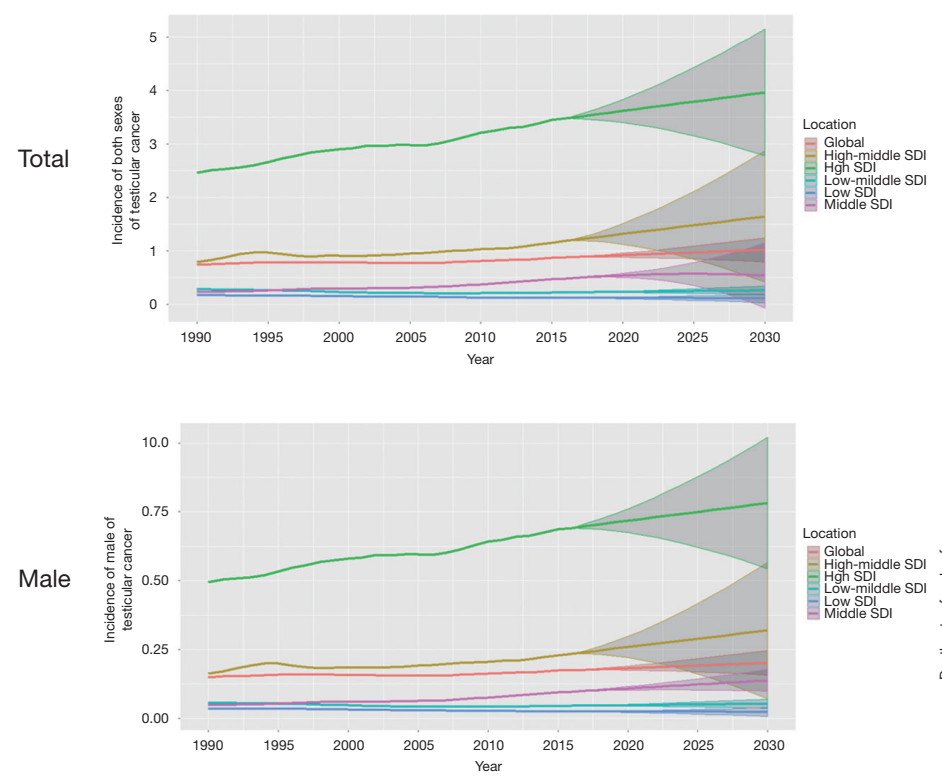

B
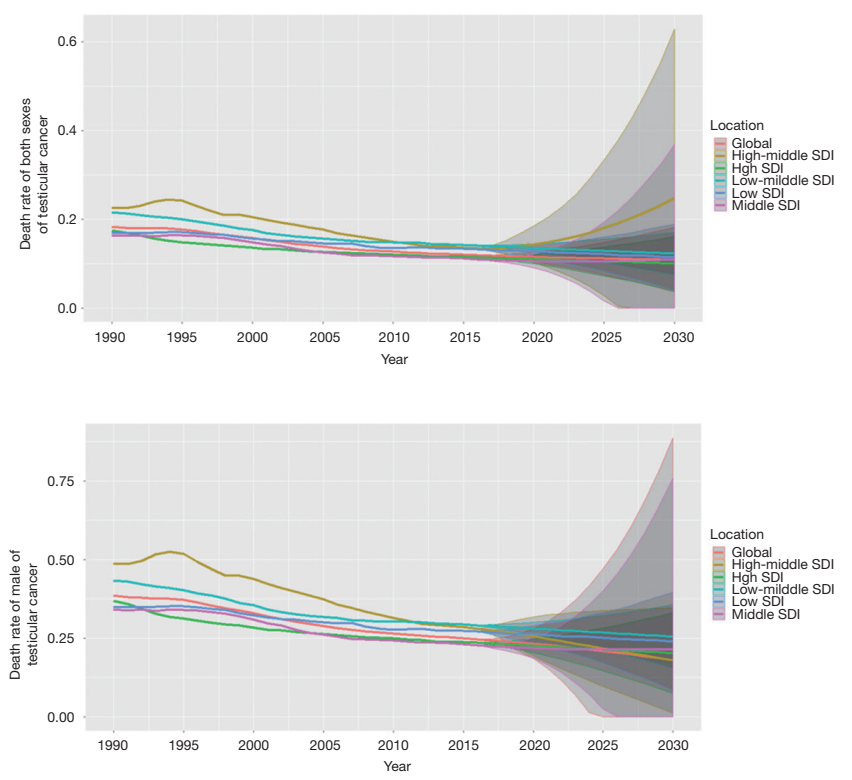

Figure 4 Global and regional trends and predictions in age-standardized incidence and death rates for testicular cancer by SDI quintile, 1990-2030. (A) Trends and predictions in age-standardized incidence rates for testicular cancer by SDI quintile, 1990-2030; (B) trends and predictions in age-standardized death rates for testicular cancer by SDI quintile, 1990-2030. SDI, sociodemographic index.

testicular cancer, this study has a great reference for the designation of testicular cancer prevention and health policies in various regions.

\section{Acknowledgments}

We thank the Global Burden of Disease Study for collection of the GBD data.

Funding: This study was funded by the National Natural Science Foundation of China (No. 91746205), IBM Global University Programs (2018 IBM Shared University Research Award), Tianjin Technical Expert Project and Hospital Innovation \& Management Research Project of Tianjin Medical University (No. 2019YG08).

\section{Footnote}

Conflicts of Interest: All authors have completed the ICMJE uniform disclosure form (available at http://dx.doi. org/10.21037/tau.2020.02.22). The authors have no conflicts of interest to declare.

Ethical Statement: The authors are accountable for all aspects of the work in ensuring that questions related to the accuracy or integrity of any part of the work are appropriately investigated and resolved.

Open Access Statement: This is an Open Access article distributed in accordance with the Creative Commons Attribution-NonCommercial-NoDerivs 4.0 International License (CC BY-NC-ND 4.0), which permits the noncommercial replication and distribution of the article with the strict proviso that no changes or edits are made and the original work is properly cited (including links to both the formal publication through the relevant DOI and the license). See: https://creativecommons.org/licenses/by-nc$\mathrm{nd} / 4.0 \%$.

\section{References}

1. Tandstad T, Dahl O, Cohn-Cedermark G, et al. Riskadapted treatment in clinical stage I nonseminomatous germ cell testicular cancer: the SWENOTECA management program. J Clin Oncol 2009;27:2122-8. Erratum in: J Clin Oncol. 2009 Jul 1;27(19):3263; J Clin Oncol. 2010 Mar 10;28(8):1438. Dosage error in article text.

2. Magelssen H, Brydøy M, Fosså SD. The effects of cancer and cancer treatments on male reproductive function. Nat 
Clin Pract Urol 2006;3:312-22.

3. Kim C, McGlynn KA, McCorkle R, et al. Sexual functioning among testicular cancer survivors: a casecontrol study in the U.S. J Psychosom Res 2012;73:68-73.

4. Pühse G, Wachsmuth JU, Kemper S, et al. Chronic pain has a negative impact on sexuality in testis cancer survivors. J Androl 2012;33:886-93.

5. Siegel RL, Miller KD, Jemal A. Cancer statistics, 2019. CA Cancer J Clin 2019;69:7-34.

6. Ghazarian AA, Kelly SP, Altekruse SF, et al. Future of testicular germ cell tumor incidence in the United States: forecast through 2026. Cancer 2017;123:2320-8.

7. Ministry of Health (2017). Cancer: Historical summary 1948-2015. Available online: https://www.health.govt.nz/ publication/cancer-historical-summary-1948-2015

8. Association of the Nordic Cancer Registries (2018). Cancer stat fact sheets: Nordic countries- Testis. Available online: http://www-dep.iarc.fr/NORDCAN/english/ frame.asp

9. GBD 2016 DALYs and HALE Collaborators. Global, regional, and national disability-adjusted life-years (DALYs) for 333 diseases and injuries and healthy life expectancy (HALE) for 195 countries and territories, 1990-2016: a systematic analysis for the Global Burden of Disease Study 2016. Lancet 2017;390:1260-344.

10. Fitzmaurice C, Allen C, Barber RM, et al. Global Burden of Disease Cancer Collaboration. Global, regional, and national cancer incidence, mortality, years of life lost, years lived with disability, and disability-adjusted life-years for 32 cancer groups, 1990 to 2015: a systematic analysis for the Global Burden of Disease Study. JAMA Oncol 2017;3:524-48.

11. GBD 2013 Mortality and Causes of Death Collaborators. Global, regional, and national age-sex specific all-cause and cause-specific mortality for 240 causes of death, 19902013: a systematic analysis for the Global Burden of Disease Study 2013. Lancet 2015;385:117-71.

12. Forouzanfar MH, Alexander L, Anderson HR, et al. Global, regional, and national comparative risk assessment of 79 behavioral, environmental and occupational, and metabolic risks or clusters of risks in 188 countries, 19902013: a systematic analysis for the Global Burden of Disease Study 2013. Lancet 2015;386:2287-323.

13. GBD 2016 Causes of Death Collaborators. Global, regional, and national age-sex specific mortality for 264 causes of death, 1980-2016: a systematic analysis for the Global Burden of Disease Study 2016. Lancet 2017;390:1151-210.
14. Global Burden of Disease Cancer Collaboration, Fitzmaurice C, Dicker D, et al. The Global Burden of Cancer 2013. JAMA Oncol 2015;1:505-27.

15. Stevens GA, Alkema L, Black RE, et al. GATHER Working Group. Guidelines for Accurate and Transparent Health Estimates Reporting: the GATHER statement. PLoS Med 2016;13:e1002056.

16. GBD 2016 Disease and Injury Incidence and Prevalence Collaborators. Global, regional, and national incidence, prevalence, and years lived with disability for 328 diseases and injuries for 195 countries, 1990-2016: a systematic analysis for the Global Burden of Disease Study 2016. Lancet 2017;390:1211-59.

17. GBD 2016 Risk Factors Collaborators. Global, regional, and national comparative risk assessment of 84 behavioral, environmental and occupational, and metabolic risks or clusters of risks, 1990-2016: a systematic analysis for the Global Burden of Disease Study 2016. Lancet 2017;390:1345-422.

18. Global Burden of Disease Cancer Collaboration, Fitzmaurice C, Akinyemiju TF, et al. Global, Regional, and National Cancer Incidence, Mortality, Years of Life Lost, Years Lived With Disability, and Disability-Adjusted LifeYears for 29 Cancer Groups, 1990 to 2016: A Systematic Analysis for the Global Burden of Disease Study. JAMA Oncol 2018;4:1553-68.

19. Coleman MP, Quaresma M, Berrino F, et al. Cancer survival in five continents: a worldwide population-based study (CONCORD). Lancet Oncol 2008;9:730-56.

20. National Cancer Institute. SEER Stat Fact Sheets: Testis Cancer. Available online: http://seer.cancer.gov/statfacts/ html/testis.html. Accessed May 28, 2015.

21. Cook MB, Akre O, Forman D, et al. A systematic review and meta-analysis of perinatal variables in relation to the risk of testicular cancer-experiences of the son. Int J Epidemiol 2010;39:1605-18.

22. Smith ZL, Werntz RP, Eggener SE. Testicular Cancer: Epidemiology, Diagnosis, and Management. Med Clin North Am 2018;102:251-64.

23. Dogra VS, Gottlieb RH, Oka M, et al. Sonography of the scrotum. Radiology 2003;227:18-36.

24. Hemminki K, Li X. Familial risk in testicular cancer as a clue to a heritable and environmental aetiology. Br J Cancer 2004;90:1765-70.

25. Bosl GJ, Motzer RJ. Testicular germ-cell cancer. N Engl J Med 1997;337:242-53.

26. Turnbull C, Rahman N. Genome-wide association studies provide new insights into the genetic basis of testicular 
germ-cell tumour. Int J Androl 2011;34:e86-96; discussion e96-7.

27. Greene MH, Kratz CP, Mai PL, et al. Familial testicular germ cell tumors in adults: 2010 summary of genetic risk factors and clinical phenotype. Endocr Relat Cancer 2010;17:R109-21.

28. Henderson BE, Benton B, Jing J, et al. Risk factors for cancer of the testis in young men. Int J Cancer 1979;23:598.

29. Petridou E, Roukas KI, Dessypris N, et al. Baldness and other correlates of sex hormones in relation to testicular cancer. Int J Cancer 1997;71:982.

30. Coupland CA, Forman D, Chilvers CE, et al. Maternal risk factors for testicular cancer: a population-based casecontrol study(UK). Cancer Causes Control 2004;15:277.

31. Møller H, Skakkebaek NE. Testicular cancer and cryptorchidism in relation to prenatal factors: case-control

Cite this article as: Cai Q, Chen Y, Zhang D, Pan J, Xie Z, Xu C, Li S, Zhang X, Gao Y, Hou J, Guo X, Zhou X, Zhang B, Ma F, Zhang W, Lin G, Xin Z, Niu Y, Wang Y. Estimates of over-time trends in incidence and mortality of testicular cancer from 1990 to 2030. Transl Androl Urol 2020;9(2):182-195. doi: 10.21037/tau.2020.02.22 studies in Denmark. Cancer Causes Control 1997;8:904.

32. Zhang Y, Graubard BI, Klebanoff MA. Maternal hormone levels among populations at high and low risk of testicular germ cell cancer. Br J Cancer 2005;92:1787.

33. Aschim EL, Grotmol T, Tretli S, et al. Is there an association between maternal weight and the risk of testicular cancer? An epidemiologic study of Norwegian data with emphasis on World War II. Int J Cancer 2005;116:327.

34. Swerdlow AJ, De Stavola BL, Swanwick MA, et al. Risks of breast and testicular cancers in young adult twins in England and Wales:evidence on prenatal and genetic aetiology. Lancet 1997;350:1723.

35. Swerdlow AJ,Skeet RG. Occupational associations of testicular cancer in southeast England. Br J Ind Med 1988;45:225. 
Table S1 GATHER Guidelines checklist

\begin{tabular}{l}
\hline Objectives and funding \\
\hline 1. Define the indicator(s), populations (including age, sex, and geographic entities), and time \\
period(s) for which estimates were made \\
2. List the funding sources for the work \\
Data inputs \\
For all data inputs from multiple sources that are synthesized as part of the study \\
3. Describe how the data were identified and how the data were accessed \\
4. Specify the inclusion and exclusion criteria. Identify all ad-hoc exclusions \\
5. Provide information about all included data sources and their main characteristics. For \\
each data source used, report reference information or contact name/institution, population \\
represented, data collection method, year(s) of data collection, sex and age range, diagnostic \\
criteria or measurement method, and sample size, as relevant \\
6. Identify and describe any categories of input data that have potentially important biases (e.g., - \\
based on characteristics listed in item 5)
\end{tabular}

For data inputs that contribute to the analysis but were not synthesized as part of the study

7. Describe and give sources for any other data inputs

For all data inputs

8. Provide all data inputs in a file format from which data can be efficiently extracted (e.g., a spreadsheet rather than a PDF), including all relevant meta-data listed in item 5. For any data inputs that cannot be shared because of ethical or legal reasons, such as third-party ownership, provide a contact name or the name of the institution that retains the right to the data

Data analysis

9. Provide a conceptual overview of the data analysis method. A diagram may be helpful

10. Provide a detailed description of all steps of the analysis, including mathematical formulae. This description should cover, as relevant, data cleaning, data pre-processing, data adjustments and weighting of data sources, and mathematical or statistical model(s)

11. Describe how candidate models were evaluated and how the final model(s) were selected

12. Provide the results of an evaluation of model performance, if done, as well as the results of any relevant sensitivity analysis

13. Describe methods of calculating uncertainty of the estimates. State which sources of uncertainty were, and were not, accounted for in the uncertainty analysis

14. State how analytic or statistical source code used to generate estimates can be accessed Results and discussion

15. Provide published estimates in a file format from which data can be efficiently extracted

16. Report a quantitative measure of the uncertainty of the estimates (e.g., uncertainty intervals)

17. Interpret results in light of existing evidence. If updating a previous set of estimates, describe the reasons for changes in estimates

18. Discuss limitations of the estimates. Include a discussion of any modelling assumptions or data limitations that affect interpretation of the estimates

Reported in the manuscript/Supplementary materials

http://ghdx.healthdata.org/gbd-2016/data-input-sources

See main manuscript

http://ghdx.healthdata.org/gbd-2016/data-input-sources

http://ghdx.healthdata.org/gbd-2016/data-input-sources

See Supplementary materials "CODEm models"; see Table S2: Covariates selected for CODEm for each GBD testicular cancer group and expected direction of covariate

See Table S3: Results for CODEm model testing

$-$

http://ghdx.healthdata.org/gbd-2016-code

GBD 2016 estimates are available online (http://vizhub.healthdata. org/gbdcompare).

Done

Table S4: Comparison of GBD 2015 and GBD 2016 covariates used and level of covariates; table online: http://fp.amegroups.cn/cms/23 6a29d20a4eb14f040340fbf5255b3b/tau.2020.02.22-1.docx

See main manuscript "Limitations"

GATHER, Guidelines for Accurate and Transparent Health Estimates Reporting; CODEm, cause of death ensemble model; GBD, Global Burden of Disease data base. 
Table S2 Covariates selected for CODEm for each GBD testicular cancer group and expected direction of covariate

\begin{tabular}{llllll}
\hline Cause & Sex & Age start & Age end & Direction & Covariate \\
\hline Testicular cancer & Male & $15-19$ years & $95+$ years & 1 & Cumulative cigarettes (10 years) \\
Testicular cancer & Male & $15-19$ years & $95+$ years & 1 & Cumulative cigarettes (15 years) \\
Testicular cancer & Male & $15-19$ years & $95+$ years & 1 & Cumulative cigarettes (5 years) \\
Testicular cancer & Male & $15-19$ years & $95+$ years & -1 & Education (years per capita) \\
Testicular cancer & Male & $15-19$ years & $95+$ years & -1 & Fruits (kcal per capita) \\
Testicular cancer & Male & $15-19$ years & $95+$ years & -1 & Health System Access 2 (unitless) \\
Testicular cancer & Male & $15-19$ years & $95+$ years & -1 & LDI (I\$ per capita) \\
Testicular cancer & Male & $15-19$ years & $95+$ years & -1 & Vegetables (kcal per capita) \\
Testicular cancer & Male & $15-19$ years & $95+$ years & 0 & Sociodemographic index \\
Testicular cancer & Male & $15-19$ years & $95+$ years & -1 & Healthcare access and quality index \\
\hline
\end{tabular}

CODEm, cause of death ensemble model; GBD, Global Burden of Disease data base.

Table S3 Results for CODEm model testing

\begin{tabular}{|c|c|c|c|c|c|c|c|c|c|}
\hline \multirow{2}{*}{ Cause } & \multirow{2}{*}{ Sex } & \multirow{2}{*}{ Age start } & \multirow{2}{*}{ Age end } & \multicolumn{6}{|c|}{ Predictive validity } \\
\hline & & & & RMSE in & RMSE out & Trend in & Trend out & Coverage in & Coverage out \\
\hline $\begin{array}{l}\text { Testicular cancer } \\
\text { (global) }\end{array}$ & Male & $15-19$ years & $95+$ years & 0.328371 & 0.529164 & 0.255569 & 0.25659 & 0.999375 & 0.995125 \\
\hline $\begin{array}{l}\text { Testicular cancer } \\
\text { (data rich) }\end{array}$ & Male & $15-19$ years & $95+$ years & 0.283022 & 0.371326 & 0.232189 & 0.243099 & 0.999645 & 0.999282 \\
\hline
\end{tabular}

CODEm, cause of death ensemble model; RMSE, root mean square of errors.

Table S4 Comparison of GBD 2015 and GBD 2016 covariates used and level of covariates

\begin{tabular}{|c|c|c|c|c|c|c|c|c|}
\hline \multirow{2}{*}{ Cause } & \multirow{2}{*}{ Sex } & \multirow{2}{*}{ Covariate } & \multicolumn{3}{|c|}{ GBD 2015} & \multicolumn{3}{|c|}{ GBD 2016} \\
\hline & & & Level 1 & Level 2 & Level 3 & Level 1 & Level 2 & Level 3 \\
\hline Testicular cancer & Male & Cumulative cigarettes (10 years) & & $x$ & & & $x$ & \\
\hline Testicular cancer & Male & Cumulative cigarettes (15 years) & & $x$ & & & $\mathrm{x}$ & \\
\hline Testicular cancer & Male & Cumulative cigarettes (5 years) & & $x$ & & & $x$ & \\
\hline Testicular cancer & Male & Education (years per capita) & & & $x$ & & & $x$ \\
\hline Testicular cancer & Male & Fruits (kcal per capita) & & $x$ & & & $x$ & \\
\hline Testicular cancer & Male & Health System Access 2 (unitless) & & $x$ & & & $x$ & \\
\hline Testicular cancer & Male & LDI (I\$ per capita) & & & $x$ & & & $x$ \\
\hline Testicular cancer & Male & Vegetables (kcal per capita) & & $x$ & & & $x$ & \\
\hline Testicular cancer & Male & Sociodemographic index & & & $x$ & & & $x$ \\
\hline
\end{tabular}

GBD, Global Burden of Disease data base.

Table S5 List of International Classification of Diseases (ICD) codes mapped to the Global Burden of Disease cause list for testicular cancer incidence and mortality data

\begin{tabular}{lll}
\hline Cause & ICD-10 & ICD9 \\
\hline Incidence & C62-C62.9, D29.2-D29.8, D40.1-D40.8 & 186-186.9, 222.0, 222.3, 236.4 \\
Mortality & C62-C62.92, Z80.43, Z85.47-Z85.48 & $186-186.9$, V10.47-V10.48, V16.43 \\
\hline
\end{tabular}




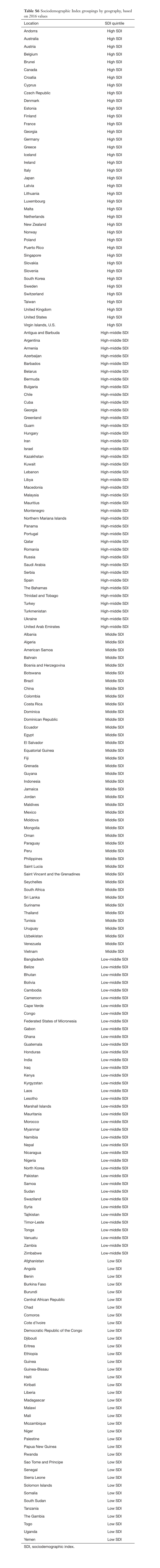


Table S7 Disability weights

\begin{tabular}{|c|c|c|c|c|}
\hline \multirow{2}{*}{$\begin{array}{l}\text { Health state } \\
\text { Cancer, diagnosis and primary therapy }\end{array}$} & \multirow{2}{*}{$\begin{array}{l}\text { Lay description } \\
\text { Has pain, nausea, fatigue, weight loss and high anxiety }\end{array}$} & \multirow{2}{*}{$\begin{array}{l}\text { Estimate } \\
0.288\end{array}$} & \multicolumn{2}{|c|}{ Uncertainty interval } \\
\hline & & & 0.193 & 0.399 \\
\hline Cancer, controlled phase & Has a chronic disease that requires medication every day and causes some worry but minimal interference with daily activities & 0.049 & 0.031 & 0.072 \\
\hline Cancer, metastatic & Has severe pain, extreme fatigue, weight loss and high anxiety & 0.451 & 0.307 & 0.600 \\
\hline Terminal phase, with medication & $\begin{array}{l}\text { Has lost a lot of weight and regularly uses strong medication to avoid constant pain. The person has no appetite, feels nauseous, and needs } \\
\text { to spend most of the day in bed }\end{array}$ & 0.540 & 0.377 & 0.687 \\
\hline
\end{tabular}

Table S8 Decomposition analysis of testicular cancer incidence trends at the global and regional levels, and by SDI quintile, both sexes, 2006 to 2016

\begin{tabular}{|c|c|c|c|c|c|c|c|c|c|}
\hline \multirow[b]{2}{*}{ Location } & \multirow[b]{2}{*}{ Cancer } & \multicolumn{2}{|c|}{ Incidence cases, No. } & \multicolumn{2}{|c|}{ Expected incidence cases, 2016, No. } & \multicolumn{3}{|c|}{ Change in incidence cases, 2006 to $2016, \%$} & \multirow{2}{*}{$\begin{array}{c}\text { Overall } \\
\text { change, } \%\end{array}$} \\
\hline & & 2006 & 2016 & $\begin{array}{l}\text { Given population } \\
\text { growth alone }\end{array}$ & $\begin{array}{l}\text { Given population } \\
\text { growth and aging }\end{array}$ & $\begin{array}{l}\text { Due to population } \\
\text { growth }\end{array}$ & $\begin{array}{c}\text { Due to change in age } \\
\text { structure }\end{array}$ & $\begin{array}{l}\text { Due to change in } \\
\text { incidence rate }\end{array}$ & \\
\hline Global & Testicular cancer & $51,202(50,063$ to 52,400$)$ & $66,833(64,487$ to 69,736$)$ & 57,565 & 58,744 & 12.4 & 2.3 & 15.8 & 30.5 \\
\hline High SDI & Testicular cancer & $29,422(28,417$ to 30,391$)$ & $34,681(32,921$ to 36,935$)$ & 30,993 & 29,738 & 5.3 & -4.3 & 16.8 & 17.9 \\
\hline High-middle SDI & Testicular cancer & $11,199(10,758$ to 11,673$)$ & $15,610(14,831$ to 16,376$)$ & 12,441 & 12,739 & 11.1 & 2.7 & 25.6 & 39.4 \\
\hline Middle SDI & Testicular cancer & $6,982(6,768$ to 7,280$)$ & $11,740(11,334$ to 12,177$)$ & 7,494 & 7,715 & 7.3 & 3.2 & 57.6 & 68.1 \\
\hline Low-middle SDI & Testicular cancer & $3,269(3,101$ to 3,471$)$ & $4,198(3,965$ to 4,480$)$ & 3,812 & 4,035 & 16.6 & 6.8 & 5 & 28.4 \\
\hline Low SDI & Testicular cancer & 538 (479 to 613 ) & 651 (590 to 734 ) & 711 & 730 & 32.3 & 3.5 & -14.8 & 21 \\
\hline
\end{tabular}

Data in the parentheses indicates $95 \%$ uncertainty interval $(95 \% \mathrm{UI})$. SDI, sociodemographic index.

Table S9 Probability of developing testicular cancer within selected age intervals, global, and by SDI quintile, by sex, 2006-2016 in \% (odds)

\begin{tabular}{|c|c|c|c|c|c|c|c|c|c|c|c|c|c|}
\hline \multirow{2}{*}{$\begin{array}{l}\text { Location/SDI } \\
\text { quintile }\end{array}$} & \multirow{2}{*}{ Cancer } & \multicolumn{2}{|c|}{ Birth to age 49} & \multicolumn{2}{|c|}{ Age 50 to 59} & \multicolumn{2}{|c|}{ Age 60 to 69} & \multicolumn{2}{|c|}{ Age 70 to 79} & \multicolumn{2}{|c|}{ Age 30 to 70} & \multicolumn{2}{|c|}{ Birth to age 79} \\
\hline & & Male & Female & Male & Female & Male & Female & Male & Female & Male & Female & Male & Female \\
\hline Global & Testicular cancer & $0.10(1$ in 1,010$)$ & NA & $0.01(1$ in 7,006$)$ & NA & 0.01 (1 in 8,191) & NA & $0.01(1$ in 7,480$)$ & NA & $0.10(1$ in 1,018$)$ & NA & 0.14 (1 in 720) & NA \\
\hline High-middle SDI & Testicular cancer & $0.13(1$ in 748$)$ & NA & $0.02(1$ in 6,624$)$ & NA & $0.02(1$ in 5,655$)$ & NA & $0.02(1$ in 4,851$)$ & NA & $0.13(1$ in 780$)$ & NA & 0.19 (1 in 535) & NA \\
\hline High SDI & Testicular cancer & 0.43 (1 in 232) & NA & 0.04 (1 in 2,226$)$ & NA & $0.02(1$ in 4,538$)$ & NA & 0.01 (1 in 7,198$)$ & NA & 0.33 (1 in 306) & NA & 0.51 (1 in 195) & NA \\
\hline Low-middle SDI & Testicular cancer & $0.02(1$ in 4,905$)$ & NA & $0.00(1$ in 27,489$)$ & NA & $0.00(1$ in 20,556$)$ & NA & 0.01 (1 in 13,863$)$ & NA & 0.03 (1 in 3,535$)$ & NA & 0.04 (1 in 2,770$)$ & NA \\
\hline Low SDI & Testicular cancer & 0.01 (1 in 9,844) & NA & $0.00(1$ in 33,316$)$ & NA & $0.00(1$ in 22,247$)$ & NA & 0.01 (1 in 16,688$)$ & NA & $0.02(1$ in 5,007$)$ & NA & $0.02(1$ in 4,229$)$ & NA \\
\hline Middle SDI & Testicular cancer & $0.05(1$ in 1,942$)$ & NA & 0.01 (1 in 16,097$)$ & NA & 0.01 ( 1 in 11,812$)$ & NA & $0.01(1$ in 7,482$)$ & NA & 0.05 (1 in 1,892$)$ & NA & $0.08(1$ in 1,258$)$ & NA \\
\hline
\end{tabular}

SDI, sociodemographic index. 